ECONOMÍA: TeOría y Práctica • Nueva Época, número 45, julio-diciembre 2016, pp. 137-167, http://www.izt.uam.mx/economiatyp/ojs

\title{
Participación laboral de personas en situación de discapacidad. Análisis desde un enfoque de género para Colombia*
}

\section{Employabitily of Persons with Disabilities. Analysis from a Gender Perspective for Colombia}

\author{
Óscar Andrés Espinosa Acuña**
}

\begin{abstract}
RESUMEN
El presente artículo estima el impacto de tener discapacidades sobre la probabilidad de estar laboralmente activo en Colombia, a partir de la Encuesta de Calidad de Vida 2013, desde un enfoque de género. Se estiman diferentes modelos de regresión logística que incluyen, además de las características sociodemográficas, nueve diferentes tipos de discapacidad permanente. Entre los resultados más importantes, destacan una alta correlación positiva, para ambos sexos, entre los niveles de formación y la participación laboral, así como el impacto negativo de las limitaciones de movilidad y habla, en el caso de las mujeres, y de los problemas mentales o de aprendizaje en el de los hombres. Las recomendaciones de política son fortalecer los programas de inserción de madres en condición de discapacidad al mercado laboral y la creación de estrategias de apoyo para personas con más de una limitación permanente.
\end{abstract}

Palabras clave: Participación laboral, discapacidad, género, mercado laboral, Encuesta de Calidad de Vida.

Clasificación JEL: J14, J16, J71.

\begin{abstract}
This paper estimates the effect of having disabilities in the probability of being employable in Colombia, from the Encuesta de Calidad de Vida (Quality of Life Survey) 2013, following a gender approach. Different logistic regression models are estimated, including not only sociodemographic characteristics, but nine different types of permanent limitation. Among the most important results standing out are that the high levels of instruction have a positive effect on labor force participation, for both sexes, and the negative impact of disabilities related to mobility and speech in the case of women, and mental issues or learning difficulties in the case of men. Policy suggestions are to strengthen the labor market inclusion programs for disabled mothers and creating strategies to support individuals with more than one permanent limitation.
\end{abstract}

Keywords: Employable, disability, gender, public policy, Encuesta de Calidad de Vida. JEL classification: J14, J16, J71.

* Fecha de recepción: 06/05/2015. Fecha de aprobación: 06/04/2016. El autor agradece a los profesores Miguel Malo, economista de la OIT y catedrático de la Universidad de Salamanca; Nikolaos Georgantzís, de la University of Reading; Óscar Melo, de la Universidad Nacional de Colombia; Fernando Urrea, de la Universidad del Valle, y a los dos revisores anónimos de eтyP por sus valiosos consejos y sugerencias en el transcurso de la investigación.

** Universidad Nacional de Colombia. Correo electrónico: oaespinosaa@unal.edu.co. 


\section{INTRODUCCIÓN}

La naturaleza y las posibles causas de la participación en el mercado laboral tienen trascendentales consecuencias en la calidad de vida de los hogares y, en especial, para grupos vulnerables, como el de las personas en condición de discapacidad. ${ }^{1}$ Su estudio se vuelve imperativo por la importancia de los efectos directos e indirectos que tiene la percepción, o no, de un ingreso por trabajar, tornándose así en un área vital de política pública que debe estar en constante revisión.

En general, se piensa que las diferentes situaciones que padecen estas personas implican severas desventajas para su participación laboral, siendo una de las razones principales la dificultad para adaptarse a las tecnologías de producción vigentes en cada época de la historia. Esto conllevaba a que las personas en condición de discapacidad tuvieran una alta probabilidad de verse obligadas a vivir en condiciones de pobreza o a emplearse en trabajos muy específicos, poco seguros y no muy bien remunerados (Malo, 2004).

Con el transcurso del tiempo, y primordialmente desde finales del siglo xx y principios del actual, en diferentes regiones del mundo se han emprendido iniciativas para minimizar los riesgos que puedan afrontar las personas en condición de discapacidad en diferentes ámbitos cotidianos (económicos, sociales, culturales, etcétera). Ejemplo de ello son algunas de las leyes antidiscriminación promulgadas en Estados Unidos (EU), como la Americans with Disabilities Act of 1990 (Ley de Estadounidenses con Discapacidades de 1990) y la Section 504 of the Rehabilitation Act of 1973 (Sección 504 de la Ley de Rehabilitación de 1973), así como el monitoreo que realizan el National Council on Disability (Consejo Nacional de la Discapacidad) y la us Agency for International Development (Agencia Estadounidense para el Desarrollo Internacional) de la adopción y seguimiento de medidas para integrar a las personas en condición de discapacidad al mercado de trabajo, aprovechando su potencial laboral (Frieden, 2003).

\footnotetext{
${ }^{1}$ Según la Organización Mundial de la Salud (Organización Mundial de la Salud, 2011), se considera personas en condición de discapacidad a quienes presentan deficiencias, limitaciones de la actividad y restricciones en la participación. Para la Organización Internacional del Trabajo (ОIT), las personas con discapacidad en el trabajo son "[...] aquellas cuyas perspectivas de seguridad, regreso, mantenimiento y progreso en un empleo adecuado se ven reducidas de forma importante debido a un reconocimiento adecuado de una discapacidad física, sensorial, intelectual o mental" (Cazes-Chaigne, 2007).
} 
En el viejo continente, años atrás se concibió la Estrategia Europea para el Empleo y para la Inclusión Social, ${ }^{2}$ que tiene por objetivo concertar tácticas y dar opciones de políticas públicas para combatir la baja tasa de empleo y la inactividad de las personas en condición de discapacidad. En el Reino Unido y Noruega, por ejemplo, a través de programas como Route to Work (Itinerario hacia el Trabajo), de 2006, y Arbeid med bistand (Trabajar con Asistencia), de 1992, respectivamente, se ha buscado incentivar a estas personas para que ingresen al mercado laboral, ayudándolos a buscar entrevistas de empleo y proporcionándoles asesoría (Cazes-Chaigne, 2007; Organización Mundial de la Salud, 2011).

En África, la Organización Internacional del Trabajo (OIT) lleva a cabo en países como Etiopía, Kenia, Tanzania, Uganda, y Zambia, un proyecto de ayuda técnica llamado Desarrollo de la Cooperación entre las Mujeres con Discapacidades, para ofrecer nuevas oportunidades de empleo mediante la capacitación en la microempresa y la asesoría en temas de microfinanzas (Cazes-Chaigne, 2007). A su vez, en Oceanía, resalta el programa australiano National Disability Strategy 2010-2020 (Estrategia Nacional sobre Discapacidad 2010-2020), que tiene por finalidad establecer un marco de política de mediano plazo para mejorar la calidad de vida y la inserción laboral de los ciudadanos en condición de discapacidad, sus familias y sus cuidadores (Council of Australian Governments, 2011). En Sudamérica, una de las regiones con más leyes en materia de discapacidad, pero donde más distancia existe entre las legislaciones nacionales y la realidad de los países (Stang, 2011; Lugo y Seijas, 2012), destacan programas como el Pacto de Productividad, en Colombia, ${ }^{3}$ el Programa Senac de Acessibilidade, en Brasil, y Red Incluye, en Chile (Organización Iberoamericana de Seguridad Social, 2014).

Actualmente, según estudios de la Organización Mundial de la Salud (OMS) aproximadamente mil millones de seres humanos padecen algún tipo de discapacidad, es decir, aproximadamente $15 \%$ de la población mundial, la mayoría de los cuales son mujeres, niños y personas pobres de avanzada edad. Asimismo, se demuestra que su número está en aumento, principalmente por el envejecimiento y el aumento de enfermedades crónicas (Organización Mundial de la Salud, 2013). Respecto al mercado laboral, a inicios de la presente década, los datos a nivel global muestran que la tasa de empleo era más baja para las

\footnotetext{
${ }^{2}$ Cada país europeo apoya su ejecución, a través del respectivo Plan Nacional de Acción para el Empleo y para la Inclusión Social.

${ }^{3}$ Tiene por objetivo incentivar el desarrollo empresarial de personas en condición de discapacidad con el apoyo del Banco Interamericano de Desarrollo (BID).
} 
mujeres (20\%) y los hombres en condición de discapacidad (53\%), que para mujeres y hombres sin discapacidad, manifestándose, de esta manera, una continua y preocupante exclusión socioeconómica (Organización Mundial de la Salud, 2011). ${ }^{4}$

Así, con el objetivo de examinar la relevancia de los diferentes factores que influyen en la incorporación de personas en condición de discapacidad en el mercado laboral de Colombia -y como uno de los primeros esfuerzos para abordar este tópico en ese país- el presente trabajo realiza un análisis de la participación en dicho mercado, con el fin de aclarar el panorama actual en este ámbito y contribuir a determinar de una mejor manera acciones y planes de política social por parte de los organismos públicos y privados pertinentes. Por otra parte, la importancia de hacerlo con una perspectiva de género radica esencialmente en la necesidad e importancia que debe darse al estudio riguroso de los temas de discapacidad, con el objetivo de que los organismos gubernamentales dispongan de mayor información y un mejor conocimiento técnico para la estructuración de políticas encaminadas a integrar a mujeres y hombres en condición de discapacidad a la comunidad y, más específicamente, al mercado laboral. Por ende, las principales preguntas de investigación a responder en este artículo son: 1) ¿La condición de discapacidad y el género se encuentran asociados con la presencia de discriminación en el mercado laboral colombiano? 2) Al existir una baja participación de las personas con discapacidad, ¿cuáles son los principales factores que la explican?¿Se diferencian los factores según el género? 3) ¿Qué perfil permite que una de estas personas tenga mayor probabilidad de integrarse al mercado de trabajo? ${ }^{5}$

La estructura del artículo es como sigue: en la primera sección, se hace un repaso al entorno legal colombiano y a las políticas públicas de apoyo a las personas con discapacidad. La segunda, presenta una revisión de la literatura, con énfasis en ciertos referentes sobre las características de este grupo en el mercado laboral de diferentes partes del mundo. En la tercera parte, se realiza un

\footnotetext{
${ }^{4}$ En el caso de Colombia, según el Censo de Población y Vivienda de 2005, realizado por el Departamento Administrativo Nacional de Estadística (DANE), 6.4\% de la población total eran personas con discapacidad (aproximadamente 2.6 millones). De este grupo, casi $80 \%$ pertenecía a estratos socioeconómicos bajos y menos de 4\% finalizaba los 11 años de educación obligatoria (Samboni y Torres, 2015)

${ }^{5}$ Como hipótesis general para este estudio, se asume que dado el tardío e incompleto desarrollo institucional de Colombia en temas de inclusión integral de las personas en condición de discapacidad y por lo demostrado en estudios sociojurídicos como los de Garavito (2014) y Cortés (2015), este grupo puede llegar a tener una muy baja tasa de participación en el mercado laboral, para ambos géneros.
} 
análisis detallado de la base de datos a utilizar (la Encuesta de Calidad de Vida de 2013), mientras que las respectivas especificaciones econométricas y la metodología estadística se exponen en la cuarta sección. Las estimaciones y sus correspondientes interpretaciones constituyen un sexto apartado. Por último, se plantean las conclusiones junto con algunas recomendaciones de interés para la política pública nacional.

\section{BREVE REPASO AL MARCO LEGAL SOBRE PERSONAS EN CONDICIÓN DE DISCAPACIDAD EN COLOMBIA}

En Colombia, las bases normativas en materia de personas en condición de discapacidad se sentaron con el Decreto 2358 (1981), mediante el cual se da inicio al Sistema Nacional de Rehabilitación, entendido como el conjunto de entidades públicas y privadas coordinadas por el Ministerio de Salud de la época, con el fin de brindar atención en temas de rehabilitación a los habitantes del territorio nacional. No obstante, no fue sino hasta finales del siglo xx, a través de la Constitución Política de Colombia (1991), especialmente su artículo 47, que en el país se reconoció a las personas en condición de discapacidad como grupo especial, especificando la importancia que debería tener el Estado en su atención y protección, a partir políticas públicas que permitieran una inclusión social y laboral digna. ${ }^{6}$

Más tarde, la Ley 361 (1997) estableció algunos marcos jurídicos sobre las ideas de prevención, promoción, protección, asistencia y prestación de servicios sociales para las personas en condición de discapacidad. Un lustro después, se aprobó la Convención Interamericana para la Eliminación de Todas las Formas de Discriminación contra las Personas con Discapacidad, mediante la Ley 762 (2002), siguiendo a ello la adopción de la Convención sobre los Derechos de las Personas con Discapacidad, a través de la Ley 1346 (2009) y la Ley 1306 (2009), en las que se establecieron normas para la protección de quienes padecen discapacidad mental y reforzar el papel del Estado como garante de sus derechos laborales, individuales y colectivos.

Para la primera década del siglo XXI, eran pocos los avances mostrados por el Sistema Nacional de Rehabilitación, dado que su implementación, organización y funcionamiento parecían poco eficientes y de corto alcance en compara-

\footnotetext{
${ }^{6}$ A su vez, el artículo 54 establece que el Estado tiene la obligación de propiciar una digna ubicación laboral a las personas en edad de trabajar y garantizar a las personas con discapacidad el derecho a un empleo acorde con sus condiciones de salud.
} 
ción con muchas de las necesidades de la población para la que se había creado. Es por ello que a mediados de ese periodo, el gobierno colombiano retomó nuevamente el ideal de una política pública sobre discapacidad a nivel nacional, regional y local, dictando la Ley 1145 (2007), por medio de la cual se organizó el Sistema Nacional de Discapacidad ${ }^{7}$ (Organización Iberoamericana de Seguridad Social, 2014), con el fin de incrementar la cobertura del apoyo y hacer más eficaces los programas de seguimiento a la población vulnerable.

En términos de marco legal laboral, se encuentran dos escritos fundamentales: los documentos Conpes 80, de 2004, y Conpes 166, de 2013 (Departamento Nacional de Planeación, 2004; 2013), donde se esbozan y esquematizan conceptos estratégicos para la inserción laboral y social de las personas en condición de discapacidad, teniendo como objetivo primordial el goce pleno en condiciones de igualdad de todos los derechos humanos y el respeto a las libertades fundamentales de este grupo especial. Además del Conpes 166 -una de las más recientes leyes referentes al tema laboral-, es con la Ley 1618 (2013) ${ }^{8}$ que se busca asegurar en Colombia el pleno ejercicio de los derechos de las personas en condición de discapacidad. En este caso, son de especial relevancia las medidas que garantizan su efectivo derecho al trabajo (artículo 13), principalmente en materia de igualdad de oportunidades, acciones afirmativas y medidas de inclusión, en afinidad con la Convención sobre los Derechos de las Personas con Discapacidad (Ley 1346, 2009).

Por otra parte, algunas instancias gubernamentales, como el Ministerio de Trabajo y la Dirección General de Promoción del Trabajo del Ministerio de Salud y Protección Social, recientemente han realizado esfuerzos conjuntos para la construcción de procesos de sensibilización dirigidos a los empresarios, con el fin de orientarlos, concientizarlos y asesorarlos en la posible contratación de personas en condición de discapacidad, en especial en el caso de las mujeres, quienes, por lo general, tienen una menor participación laboral (Ministerio de la Protección Social, 2008). Asimismo, el Ministerio de Salud y Protección Social elaboró hace poco tiempo un manual sobre normas integrales de protección a

\footnotetext{
${ }^{7}$ Este sistema está conformado por: 1) el Ministerio de Salud y Protección Social, 2) el Consejo Nacional de Discapacidad, 3) los Comités Departamentales y Distritales de Discapacidad y 4) los Comités Municipales y Locales de Discapacidad.

${ }^{8}$ Es de resaltar que el artículo 7 de esta ley aborda el establecimiento de programas de apoyo y orientación para las mujeres gestantes en condición de discapacidad o con alto riesgo de adquirir una discapacidad, a través de la gestión de las Direcciones Territoriales de Salud y de la Seccional de Salud de cada departamento, distrito y municipio.
} 
quienes están en condición de discapacidad, ${ }^{9}$ con la idea de "[...] proponer y promover la ejecución de políticas de readaptación profesional y generación de empleo" (Ministerio de la Protección Social, 2010). Es de resaltar, que dentro de las sugerencias de esta institución, están el aseverar rotundamente que la discapacidad no es un impedimento para el desempeño laboral y el seguir en la tarea, todavía incompleta y compleja, de concientizar al empresariado colombiano acerca de los beneficios tributarios a que tiene derecho al emplear a las personas en esta condición (Ministerio de la Protección Social, 2010). ${ }^{10}$

\section{REVISIÓN DE LA LITERATURA}

Estudios como el que se realiza en este documento se enmarcan comúnmente en el modelo de búsqueda de empleo, en el cual el agente económico en estado de inactividad tiene por finalidad encontrar un trabajo maximizando su utilidad. Ésta depende de factores como los ingresos, el valor del tiempo de ocio, el coste monetario de buscar trabajo y el coste de tiempo (Rogerson, Shimer y Wright, 2005). Además, desde un punto de vista microeconómico, se afirma que la decisión de emplearse se encuentra determinada principalmente por características personales como la edad, el género, la educación, los hijos, los ingresos totales del hogar, entre otras (Mortensen, 1986). Por su parte, la oferta de empleo está condicionada por los requerimientos de habilidades, destrezas y conocimientos necesarios para su desempeño (Rogerson, Shimer y Wright, 2005).

Además de los factores anteriores, según la literatura académica, existen otros de gran importancia para el encuentro de actores en el mercado laboral, como la percepción y las expectativas del oferente del trabajo acerca de las potenciales calificaciones de los empleados, así como la cantidad y la calidad de la información que puedan poseer las dos partes implicadas (Dávila, 2006). En el caso de las personas en condición de discapacidad, y en mayor medida para las mujeres, el conocimiento de los problemas físicos y/o mentales de este tipo de

\footnotetext{
${ }^{9}$ Otras instituciones colaboran desde un enfoque más psicosocial integral que específicamente laboral, como el Departamento Administrativo para la Prosperidad Social (DPS), el Instituto Nacional para Sordos (INSOR), el Instituto Nacional para Ciegos (INCI), la Fundación para la Investigación y el Desarrollo de la Educación Especial (FIDES), la Fundación Creando Futuro, la Fundación Teletón Colombia y otras.

${ }^{10}$ Por ejemplo, en el quinto párrafo del artículo 3 de la Ley 1429 (2010), de Formalización y Generación de Empleo, se dicta que los jóvenes en condición de discapacidad tendrán prioridad en los programas de formación y capacitación.
} 
trabajadores afecta en gran medida la decisión del empleador. ${ }^{11}$ De igual manera, desde la perspectiva de dichas personas, su condición influye en su decisión sobre la cantidad de tiempo a invertir en el mercado laboral, distorsionando, por ende, su tasa marginal de sustitución entre bienes y ocio (Mortensen, 1986).

La literatura internacional sobre el mercado laboral para las personas en condición de discapacidad tuvo sus inicios en EU, con los estudios seminales de Grossman y Benham (1974), Bartel y Taubman (1979) y Lambrinos (1981). En ellos, se encuentran análisis económicos, tanto descriptivos como analíticos, acerca de los efectos de la salud en el mercado laboral, de lo que se desprende, entre otras deducciones importantes, que existen diferencias significativas en la probabilidad de emplearse en función del tipo de discapacidad y que las personas que sufren más de un tipo de discapacidad son, por lo general, las que están en peor situación socioeconómica. Otro hecho no menos relevante, es que se obtienen resultados muy diversos respecto a los beneficios de recibir subsidio y el correspondiente incentivo para integrarse al mercado laboral, no habiendo al día de hoy consenso sobre las consecuencias de estas transferencias.

En Europa, el tema se comenzó a estudiar a finales del siglo xx con trabajos como los de O'Donnell (1998) y Kidd, Ferko y Sloane (2000) y pocos años más tarde se amplió el número de investigaciones, contándose entre éstas las de García-Serrano y Malo (2002), Dávila (2006) y Malo y Pagán (2012). Por lo general, los sistemas de información estadística europeos permiten abordajes interesantes, que no se pueden llevar a cabo en los países en desarrollo. Dichas investigaciones coinciden en que las personas en condición de discapacidad poseen una tasa de actividad considerablemente más baja que el promedio de la población, así como un nivel de educación no muy alto.

En el caso de Latinoamérica, Asia y Oceanía, las primeras investigaciones se realizaron a inicios del siglo XXI, encontrándose artículos como los de Hernández-Licona (2001), Brazenor (2002), Wilkins (2003) y Mitra y Sambamoorthi (2008), entre otros. Aunque el número de trabajos acerca de estas regiones es limitado en comparación con los desarrollados en EU y Europa, arrojan resultados similares a los europeos. Sobre África, están los estudios de Eide, Loeb y Van Rooy (2003), Atijosan et al. (2008) y Eide y Kamaleri (2009; 2011), que reportan que las personas con discapacidad tienen condiciones de vivienda

${ }^{11}$ De acuerdo con Becker (1971), esto podría definirse como una discriminación debida principalmente a prejuicios sociales, que asocian los problemas físicos o mentales con una baja productividad y/o rendimiento laboral. 
desventajosas respecto a las de la población sin discapacidad, especialmente, por hacinamiento.

Aunque desde el principio algunos estudios han adoptado un enfoque de género, por ejemplo, el de Parsons (1984), esta perspectiva se hizo más frecuente a mediados de los noventa, con trabajos como los de Baldwin y Johnson (1994; 1995), y Loprest, Rupp y Sandell (1995). En ellos, como es de esperar y en coincidencia junto con artículos más recientes, como los de Meseguer-Santamaría et al. (2009) y Mitra y Mizunoya (2013), se encuentra que las personas en condición de discapacidad de ambos sexos tienen salarios relativamente más bajos que el resto de trabajadores, además de una baja tasa de participación laboral. A la vez, se muestra la existencia de brechas más grandes en las tasas de empleo entre hombres con y sin discapacidad que entre mujeres con y sin discapacidad.

En el caso de Colombia, aún no existen estudios que evalúen en términos cuantitativos la situación del mercado de trabajo para las personas en condición de discapacidad ${ }^{12}$ y menos desde una perspectiva de género. Por ello, el presente trabajo tiene un carácter novedoso y de amplio interés debido al gran potencial que pueden tener sus aportes para entender mejor la dinámica de este tema. Y es a partir de este enfoque que se propone establecer, desde una primera aproximación, bases rigurosas para la concreción de políticas públicas y corporativas a favor de este sector de la población, en especial del género femenino, que ha sufrido históricamente una mayor vulnerabilidad, como señala la Organización Mundial de la Salud $(2011 ; 2013)$.

\section{ANÁLISIS DE DATOS}

Para responder las preguntas de investigación anotadas en la introducción, se hace uso de la base de datos de la Encuesta de Calidad de Vida (ECV) de 2013, información proporcionada por el Departamento Administrativo Nacional de Estadística (2013a). Esta encuesta tiene por objeto “[...] recoger información sobre diferentes aspectos y dimensiones del bienestar de los hogares, incluyendo aspectos como el acceso a bienes y servicios públicos, privados o comunales, sa-

${ }^{12}$ Se han realizado estudios cuantitativos que tratan la diferenciación salarial por género en Colombia, no obstante, ninguno de ellos analiza concretamente a las personas en condición de discapacidad. Es de resaltar el documento de Econometría Consultores (2012), donde se realiza un estudio principalmente cualitativo sobre los diferentes ámbitos de actualidad (social, económico, jurídico e institucional) de estas personas en el país. 
lud, educación, cuidado de niños y niñas menores de cinco años, entre otros" (Departamento Administrativo Nacional de Estadística, 2013b, p. 8).

La ECV 2013 cuenta con una muestra de 21565 hogares con encuestas completas y es representativa para el total nacional y las grandes regiones, como Antioquia, Valle, Atlántico, Pacífica, Central y Oriental; cada desagregación es representativa a nivel de cabecera (área metropolitana, área urbana y cabecera municipal) y otras demarcacioners (centros urbanos, caseríos, inspecciones de policía, corregimiento municipal y área rural dispersa). A su vez, en las regiones Orinoquía-Amazonía, Bogotá, DC, y San Andrés, la encuesta tiene en cuenta sólo la cabecera (Departamento Administrativo Nacional de Estadística, 2013a).

Su base de datos se divide en once diccionarios: 1) Datos de la vivienda. 2) Servicios del hogar. 3) Tenencia y financiación de la vivienda que ocupa el hogar. 4) Condiciones de vida del hogar y tenencia de bienes. 5) Otros subsidios. 6) Características y composición del hogar. 7) Salud. 6) Atención integral de los niños y niñas menores de cinco años. 9) Educación. 10) Fuerza de trabajo y 11) Tecnologías de información y comunicación.

\section{Cuadro 1. Población en edad de trabajar por género y condición de discapacidad (porcentaje)}

\begin{tabular}{lccc} 
& Población general & Población discapacitada & Población sin discapacidad \\
\hline Mujeres & 52.02 & 48.68 & 52.23 \\
Hombres & 47.98 & 51.32 & 47.77 \\
\hline
\end{tabular}

Fuente: Elaboración propia con información de la ECV 2013 (Departamento Administrativo Nacional de Estadística, 2013a).

El tópico de salud proporciona información acerca de las limitaciones permanentes, físicas y/o mentales, de los individuos, por lo que los datos de la ECV 2013 sobre diferentes tipos de discapacidad ${ }^{13}$ se considera adecuada y perti-

${ }^{13}$ En la ECV 2013 (Departamento Administrativo Nacional de Estadística, 2013a), la pregunta codificada P5693 de la sección "Salud” dice: “¿[...] tiene limitaciones permanentes para: [...]?”, y como posibles respuestas se desglosa un abanico de nueve opciones para definir qué tipo (o tipos) de discapacidad se padece. Según el DANE, este tipo de pregunta "[...] busca establecer si la persona tiene alguna limitación de forma permanente que le impida desarrollar sus actividades normales o que restrinja su participación en la vida cotidiana" (Departamento Administrativo Nacional de Estadística, 2013, p. 34), siguiendo de cerca el enfoque conceptual registrado por la Clasificación Internacional del Funcionamiento, la Discapacidad y la Salud (CIF) de la OMS. 
Cuadro 2. Participación laboral y tasa de empleo por género

\begin{tabular}{lcccc} 
& Género & Actividad & Inactividad & Tasa de empleo \\
\hline \multirow{3}{*}{ Población discapacitada } & Masculino & $13.44 \%$ & $86.56 \%$ & $12.91 \%$ \\
& Femenino & $36.39 \%$ & $63.61 \%$ & $34.26 \%$ \\
& Razón M/F & 2.71 & 0.73 & 2.66 \\
\hline \multirow{2}{*}{$\begin{array}{l}\text { Población sin } \\
\text { discapacidad }\end{array}$} & Masculino & $32.37 \%$ & $67.63 \%$ & $30.82 \%$ \\
& Femenino & $70.27 \%$ & $29.73 \%$ & $66.27 \%$ \\
& Razón M/F & 2.17 & 0.44 & 2.15 \\
\hline
\end{tabular}

Fuente: Elaboración propia con información de la ECV 2013 (Departamento Administrativo Nacional de Estadística, 2013a).

nente para los fines del estudio propuesto. La encuesta incluye 73155 registros individuales, $79.14 \%$ de los cuales corresponden a población en edad de trabajar (12 años en adelante); de ella, $52.02 \%$ son mujeres y $47.98 \%$, hombres. Similar proporción se da en la población en edad de trabajar sin discapacidad $(52.23 \%$ del sexo femenino y $47.77 \%$ del masculino, sin embargo, en el segmento en condición de discapacidad (que representa $5.16 \%$ del total), se tiene una mayor proporción de varones (51.32\%) que de mujeres (48.68\%) (cuadro 1).

En el cuadro 2 se muestran las tasas de participación laboral y empleo por género, calculadas a partir de la población en edad de trabajar. La razón mayor a uno en la columna de actividad y, por ende, menor a uno en la columna de inactividad revela diferencias laborales a favor de los hombres, especialmente en el grupo de personas en condición de discapacidad. En lo que respecta a la tasa de empleo, aunque en ambos segmentos, con y sin discapacidad, existen diferencias en contra de las mujeres, la inequidad es mayor en el primero. Asimismo, es de resaltar la brecha en la tasa de empleo entre los hombres con y sin discapacidad (con una razón de 1.93), así como entre mujeres (razón de 2.39), lo que pone de manifiesto que la situación laboral de las personas en condición de discapacidad, de ambos sexos, es mucho más difícil que la de la población sin discapacidad.

En el cuadro 3, que presenta por edad y género los diferentes tipos de discapacidad caracterizadas por la ECV 2013 (Departamento Administrativo Nacional de Estadística, 2013a), es de destacar que más de 50\% de los encuestados con limitaciones permanentes en el habla, el entendimiento o aprendizaje y con problemas mentales o emocionales están por debajo de los 45 años. Asimismo, más de $80 \%$ de la población con problemas de movimiento y escucha está compuesta por individuos con 45 años o más, lo que concuerda con el hecho de que las discapacidades avanzan con la edad. 
148 ECONOMÍA: TEORÍA Y PRÁCTICA • Nueva Época, número 45, julio-diciembre 2016

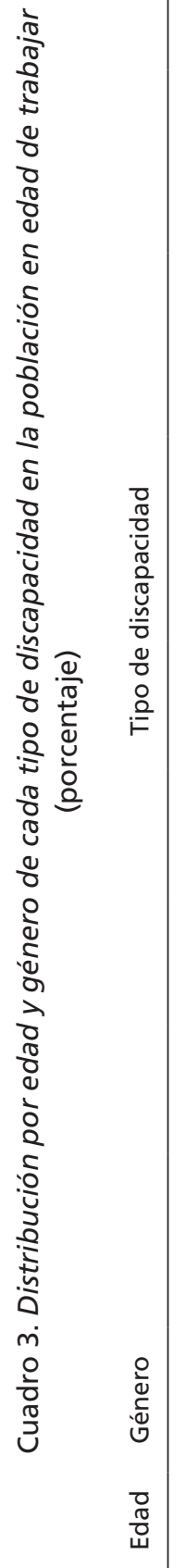

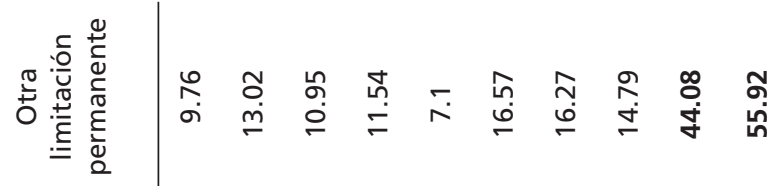

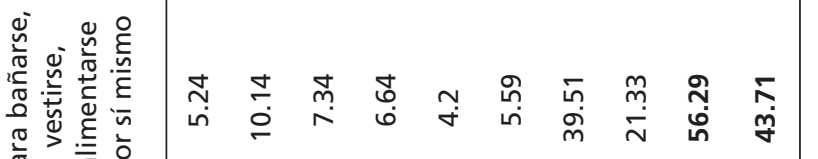

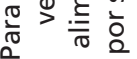

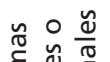

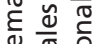

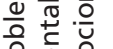

일 है

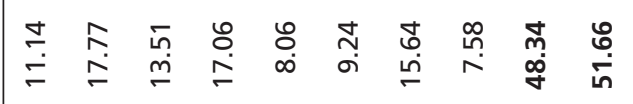

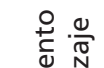

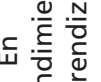

远

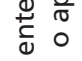

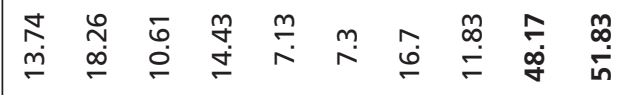

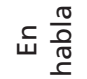

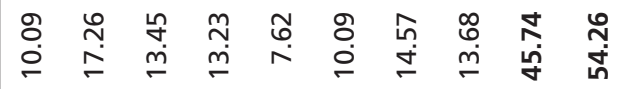

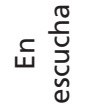

돈 $: \frac{0}{n ! n}$

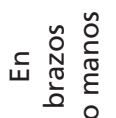

$\infty$

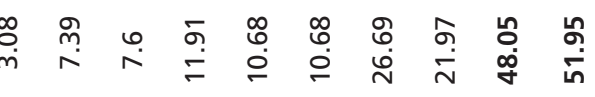

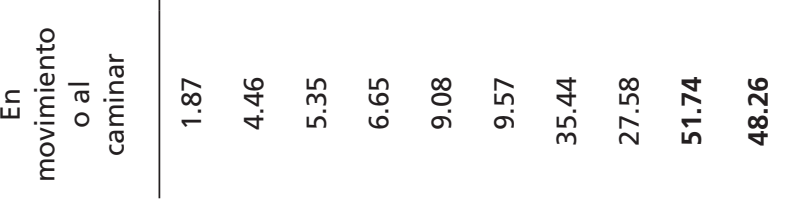

$\stackrel{\dot{\pi}}{\stackrel{ก}{0}}$

$\frac{\sqrt[0]{0}}{\frac{\pi}{0}}$

$\frac{1}{0}$

ত্

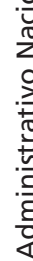

$\frac{2}{2}$

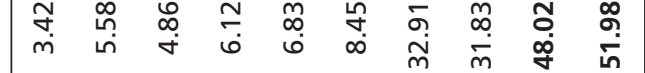

in

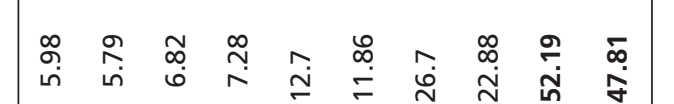

己

$\frac{0}{0}$

음 
En el mismo cuadro se observa que los porcentajes más bajos de discapacidad en el movimiento o al caminar, en los brazos o manos y en la escucha se registran en el grupo de 12 a 24 años. La situación es similar en el caso de problemas en el habla y de otra limitación permanente (segunda participación más baja) para las personas entre 25 y 44 años. Por otra parte, las últimas dos filas muestran la distribución general por género de los diferentes tipos de discapacidad, encontrándose que la incidencia de la limitación para bañarse, vestirse y alimentarse por sí mismo es la que presenta mayor diferencia (12.59\%) entre hombres y mujeres -afectando mayoritariamente a éstas-y la de menor diferencia es la dificultad de relacionarse socialmente por problemas mentales o emocionales $(3.32 \%)$.

A su vez, el cuadro 4 evidencia que las personas con discapacidad que forman parte de la población laboralmente activa cuentan con mayor edad promedio que aquellas sin discapacidad (por más de 8 años), diferencia que se amplía en el mismo sentido entre la población inactiva laboralmente (por más de 20 años). En términos de estado civil, la proporción de hombres que contraen matrimonio es mayor que la proporción de mujeres para los dos segmentos.

Los datos de este cuadro también expresan importantes diferencias en el nivel educativo entre la población en condición de discapacidad y la población sin discapacidad. Las tasas de analfabetismo son mayores, tanto para hombres como para mujeres del primer segmento y cuentan, por el contrario, con una menor cantidad de personas con estudios universitarios respecto a la población sin discapacidad. Esta información refuerza dos ideas ya bien conocidas en la literatura internacional: la primera se refiere a que tales porcentajes revelan las barreras educativas a las que tienen que enfrentarse las personas en condición de discapacidad y la segunda es que se trata una característica intrínseca de la situación vivencial de quienes padecen esta circunstancia, por los mayores problemas que tienen para terminar sus estudios (Dávila, 2006; Malo y Pagán, 2012; Mitra y Mizunoya, 2013). ${ }^{14}$ Por último, en el análisis descriptivo, se observa que el género femenino tiene mayores porcentajes de formación secundaria y universitaria, mientras que en el género masculino prima el nivel de estudios primarios, en consonancia con los resultados presentados por Kidd, Ferko y Sloane (2000), quienes indican la probable existencia de una causalidad inversa entre nivel de

\footnotetext{
${ }^{14}$ Asegura Dávila (2006, p. 140): “Aquéllos con bajos niveles educativos es más probable que ocupen trabajos manuales y que presenten una mayor proclividad a discapacidades relacionadas con el trabajo que los trabajadores no manuales con mayor nivel de formación".
} 


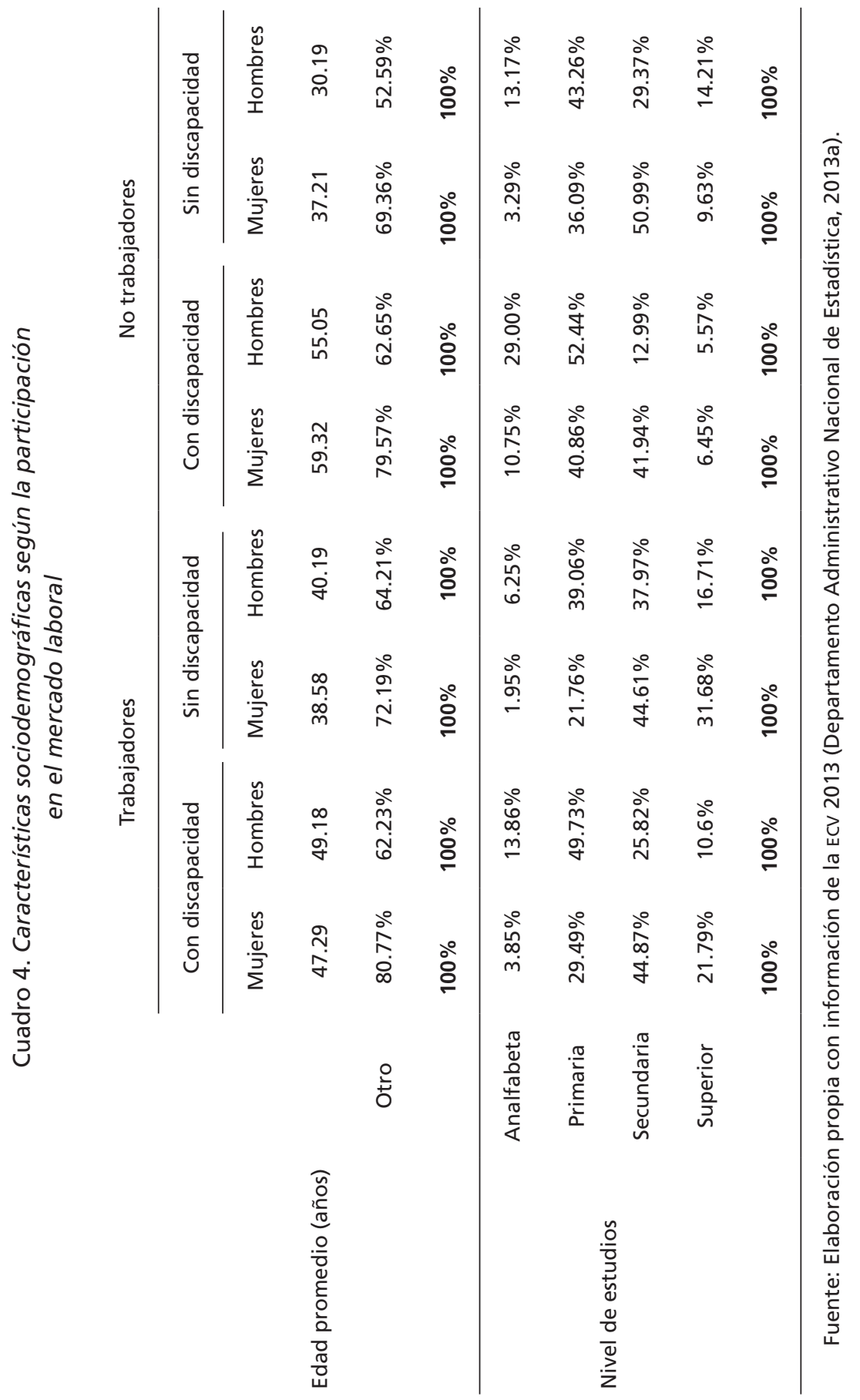


empleo y nivel de educación, en especial, para los hombres, quienes poseen una mayor tasa de actividad laboral.

\section{METOdología ESTADÍSTICA Y ESPECIFICACIÓN DE LAS ECUACIONES DE PARTICIPACIÓN}

En lo que toca a los modelos estadísticos, se construyeron diversas ecuaciones de participación en el mercado de trabajo, haciendo uso de la información de la ECV 2013 (Departamento Administrativo Nacional de Estadística, 2013a), con el fin de descubrir los factores determinantes que influyen en la inserción de las personas en condición de discapacidad. Para efectos comparativos desde una perspectiva de género, se especificaron los modelos econométricos por sexo.

En estas ecuaciones se evalúan las características sociodemográficas, el capital humano, la geografía y la tipología de discapacidad. Las variables endógenas respectivas son dicotómicas y hacen referencia a si cada encuestado participa en el mercado laboral (trabajando o buscando trabajo) o no. Así, al establecer que la variable endógena es de naturaleza cualitativa y que los sistemas estadísticos adecuados para trabajar en este caso abarcan los modelos de probabilidad probit, Tobit y logit, entre otros, se procedió a estimar regresiones logísticas, dada la oportunidad y ventaja de interpretar las razones de probabilidad relativa, también denominadas odds-ratio (OR).

La elección de un tipo de sistema estadístico de respuesta dicotómica se fundamenta en la idea de que un individuo ingresará al mercado de trabajo si, y sólo si, el ingreso laboral que puede obtener se encuentra por encima de su salario de reserva. Por lo que, de acuerdo con Malo:

El problema econométrico al que se enfrenta este planteamiento es que el salario de reserva no es directamente observable. No obstante, la propia decisión de participación sí que es observable, de manera que, aceptando este marco teórico, observamos que participan precisamente aquellos individuos para los cuales las ofertas salariales que puede obtener son superiores a su inobservado salario de reserva [...] (Malo, 2004, pp. 92-93).

En consecuencia, al observar una variable dual, como lo es participar o no participar -variable endógena en las ecuaciones (6) (7) y (8)-, se obtiene la justificación desde el punto de vista teórico para utilizar tales modelos de regresión logística. Esta técnica de análisis posee una variable endógena binaria y 
unas cuantas variables exógenas de naturaleza cualitativa y/o cuantitativa. $\mathrm{Su}$ modelación difiere del análisis de regresión tradicional al utilizar como función de estimación la función logística en vez de la lineal. Por ende, con la regresión logística, el resultado del modelo es la estimación de la probabilidad de que un individuo pertenezca a un grupo u otro (Cramer, 2011).

La función de distribución acumulada logística se define mediante:

$$
P(Y)=\frac{1}{1+e^{-\mathrm{Z}}}=\frac{e^{\mathrm{z}}}{1+e^{\mathrm{Z}}}
$$

donde $Z=\beta_{0}+\beta_{1} X_{1}+\cdots+\beta_{k} X_{k}$, puede tomar valores en el intervalo $(-\infty,+\infty)$, y $\beta_{k}$ denota el coeficiente de la variable exógena $k$. Por su parte, $P(Y)$, que denota la probabilidad de estar en una de las categorías de la variable binaria endógena, tiene un rango entre 0 y 1 , a la vez que no está relacionada linealmente con $Z$ y, por tanto, tampoco con $X$. Las razones de probabilidad relativa $O R$ se definen mediante:

$$
O R=\frac{P(Y=1)}{P(Y=0)}=\frac{\left(\frac{1}{1+e^{-Z}}\right)}{\left(1-\frac{1}{1+e^{-Z}}\right)}=\frac{\frac{1}{\left(1+e^{-\left(\beta_{0}+\beta_{1} X_{1}+\cdots+\beta_{k} X_{k}\right)}\right)}}{1-\frac{1}{\left(1+e^{-\left(\beta_{0}+\beta_{1} X_{1}+\cdots+\beta_{k} X_{k}\right)}\right)}}
$$

por lo que resulta finalmente la expresión:

$$
O R=e^{\left(\beta_{0}+\beta_{1} X_{1}+\cdots+\beta_{k} X_{k}\right)}=e^{\left(\beta_{0}+\sum_{i=1}^{k} \beta_{i} X_{i}\right)}
$$

donde $O R$, expresa el cociente de la tasa de probabilidades de estar activo o inactivo en el mercado de trabajo para dos personas con características iguales, excepto en la variable $X_{i}$. Es decir, para interpretar los coeficientes estimados del modelo logit, se divide la probabilidad de que el suceso (participación en el mercado laboral) ocurra sobre su complementario (no participación en el mercado laboral), dado el valor de una variable independiente $\left(X_{i}\right)$ y teniendo todo el resto de variables constantes (Cramer, 2011).

Para su estimación, se utiliza el método de máxima verosimilitud, que corresponde a la resolución del problema dado en (4) y, por ende, en (5):

$$
\underset{\beta}{\operatorname{Max}} P(Y \mid \boldsymbol{X})=\underset{\beta}{\operatorname{Max}}\left[\prod_{t=1}^{N} \Phi\left(\beta^{T} \boldsymbol{X}_{i}^{T}\right)\right]
$$




$$
\underset{\beta}{\operatorname{Max}} l(Y \mid \boldsymbol{X})=\operatorname{Max}_{\beta}\left[\sum_{t=1}^{N} \ln \left[\Phi\left(\beta^{T} \boldsymbol{X}_{i}^{T}\right)\right]\right]
$$

donde $N$ son los individuos de la muestra aleatoria, la función $\ln ($.) es el logaritmo natural y $l(\mathrm{Y} / \mathrm{X})$ es la función de log-verosimilitud, la cual resulta más conveniente para trabajar. Según Cramer (2011), con esta metodología, la estimación del vector de parámetros resulta ser la que maximiza (5), ${ }^{15}$ la cual, bajo condiciones bastantes generales, obtiene estimaciones consistentes, asintóticamente eficientes y asintóticamente normales. Las variables categorizadas a usar en la modelación son:

1) Edad: 12-24 años, 25-44 años, 45-59 años, 60 o más años.

2) Sexo: femenino o masculino.

3) Región: metrópolitana (Bogotá, DC, Antioquia, Valle del Cauca) y otras (Atlántica, Oriental, Central, Pacífica, San Andrés y Providencia, Orinoquia y Amazonia).

4) Ingreso per cápita del hogar: COP 0-COP 350000 , COP 350 001-COP 700000 , COP 700 001-COP 1050000 , COP 1050 001-COP 1400000 , más de COP 1400000.

5) Estado civil: casado y otro (unión libre, soltero, separado).

6) Estudios propios, de la madre y del padre: analfabetismo, primaria, secundaria, educación superior.

7) Tipo de discapacidad: para moverse o caminar; para usar brazos o manos; para ver, a pesar de usar lentes o gafas; para oír, aun con aparatos especiales; para hablar; para entender o aprender; dificultad de relacionarse con los demás por problemas mentales o emocionales, y otras.

8) Subsidio o pensión: beneficiario o no. ${ }^{16}$

De esta manera, un primer modelo a estimar evalúa la participación del total de personas con y sin discapacidad: ${ }^{17}$

\footnotetext{
${ }^{15}$ No resulta trivial resolver esto, por lo que debe solucionarse mediante métodos numéricos. En las estimaciones de este estudio, se usó el algoritmo de optimización hill climbing cuadrático.

${ }^{16}$ La variable "subsidio o pensión" se referiere a cualquier transferencia que reciba el individuo (pensiones contributivas, no contributivas y otras transferencias, siempre y cuando no estén relacionadas con el desempleo), bien sea del programa Familias en Acción, Colombia Mayor o Red Unidos, entre otros. En el caso de las mujeres, se cuenta con la variable "hijos o embarazada".

${ }^{17}$ Para cada variable se deja una categoría como referente, para evitar la multicolinealidad. Además, los tipos de discapacidad no se consideran mutuamente excluyentes, de modo que se incluyen todos como dummies en los modelos, sin tener en este caso especial categoría de referencia.
} 
Participación laboral total $=f$ (edad, nivel educativo, sexo, región, ingreso per cápita del hogar, estado civil, nivel educativo de los padres, subsidio o pensión, discapacidad)

Los siguientes modelos estiman la participación laboral de las mujeres (aunque también son aplicables al caso de los hombres) ${ }^{18}$ sin y con discapacidad a través de (7) y (8), respectivamente:

Participación laboral de mujeres sin discapacidad $=f$ (edad, nivel educativo, región, ingreso per cápita del hogar, estado civil, nivel educativo de los padres, hijos o embarazo, subsidio o pensión)

Participación laboral de mujeres con discapacidad $=f$ (edad, nivel educativo, región, ingreso per cápita del hogar, estado civil, nivel educativo de los padres, hijos o embarazo, subsidio o pensión, tipo de discapacidad)

De esta manera, se define la probabilidad de estar activo laboralmente en función de los factores que determinan las ofertas que factiblemente puede recibir un sujeto y de las variables que manifiestan el valor de su salario de reserva (Mortensen, 1986; Malo, 2004). En la siguiente sección se presenta la inferencia de las ecuaciones de participación propuestas.

\section{ANÁLISIS DE LOS RESULTADOS ECONOMÉTRICOS}

Para los diferentes resultados se calcularon las razones de probabilidad relativa (como se muestra en el cuadro 5), con el fin de facilitar la interpretación de ellos. ${ }^{19}$ Así, sobre la estimación de la ecuación (6), se observa que la probabili-

\footnotetext{
${ }^{18}$ Se muestran las ecuaciones sólo para el caso de las mujeres, dado que se sigue una estructura exactamente igual para los hombres, restándole la variable hijos, ya que no se cuenta con tal información para el género masculino.

${ }^{19}$ La columna 1/OR del cuadro 5 corresponde a los valores de la columna OR menores a 1, para hacer más comprensible su interpretación. Por otro lado, cabe resaltar que en lo que toca a la bondad de ajuste para los cinco modelos estimados en esta sección (cuadros 5, 6 y 7), la $R^{2}$ de McFadden, también conocida como pseudo- $R^{2}$ (construido a partir de $\left[1-l\left(L\left(\beta_{1}\right)\right) / l\left(L\left(\beta_{0}\right)\right)\right]$, donde $L\left(\beta_{1}\right)$ hace referencia a la log-verosimilitud del modelo completo y $L\left(\beta_{0}\right)$ se toma como el valor de la log-verosimilitud de un modelo en el que sólo se incluye una constante (McFadden, 1974)), estu-
} 
Cuadro 5. Estimaciones de la probabilidad de participar en el mercado de trabajo

Modelo de regresión logística para la población total

\begin{tabular}{l|l|l|c}
\hline \multicolumn{1}{c|}{ Variables } & Coeficiente & OR* & $1 / O R$ \\
\hline Constante & $0.3485^{* * *}$ & 1.4169 & \\
Edad (25-44 años) & $0.9250 * *$ & 2.5218 & \\
Edad (45-59 años) & $0.7693 * *$ & 2.1582 & \\
Edad (más de 59 años) & $-1.6001 * *$ & 0.2019 & 4.9537 \\
Educación padres - primaria & 0.0017 & 1.0017 & \\
Educación padres - secundaria & -0.0072 & 0.9928 & 1.0073 \\
Educación padres - superior & 0.0382 & 1.0390 & \\
Mujer & $-2.9338 * *$ & 0.0532 & 18.7996 \\
Casado & $-0.3303 * *$ & 0.7187 & 1.3913 \\
Metrópoli & $-0.1260 * *$ & 0.8817 & 1.1342 \\
Educación propia - primaria & 0.0611 & 1.0630 & \\
Educación propia - secundaria & $0.1529 * * * *$ & 1.1652 & \\
Educación propia - superior & $0.9696 * *$ & 2.6369 & \\
Ingreso per cápita (cop 350 001-COP 700 000) & $0.6461 * *$ & 1.9080 & \\
Ingreso per cápita (cop 700 001-COP 1 050 000) & $0.7394 * *$ & 2.0947 & \\
Ingreso per cápita (cop 1050001-COP 1 400 000) & $0.5727 * *$ & 1.7731 & \\
Ingreso per cápita (más de coP 1 400 001) & $0.5612 * *$ & 1.7529 & \\
Subsidio o pensión & $0.1107 * *$ & 1.1170 & \\
Sin discapacidad & $1.5472 * *$ & 4.6981 & \\
\hline$R^{2}$ de McFadden & 0.2529 & & \\
\hline
\end{tabular}

* $O R=$ razones de probabilidad relativa.

** Parámetros estadísticamente significativos para $\alpha=1 \%$.

$* * *$ Parámetros estadísticamente significativos para $\alpha=5 \%$.

$* * * *$ Parámetros estadísticamente significativos para $\alpha=10 \%$.

Nota: Porcentaje global de aciertos: $72.51 \%$. Aparte de la $R^{2}$ de McFadden, otra manera de valorar los modelos desde un enfoque más aplicado (como es el de saber si resulta útil para determinar si el sujeto está activo o no dado el valor de las variables exógenas de la ecuación) es el llamado porcentaje global de aciertos, con el cual se evalúa la capacidad de asignar 0 o 1 al caso a partir del modelo estimado frente a los datos reales, observando, así, su eficacia predictiva.

Variables de referencia: edad (12-24 años), educación padres-analfabeta; hombre, otro estado civil, otras regiones, educación propia-analfabeta, ingreso per cápita (COP 0-COP 350 000), sin subsidio ni pensión, posee una o varias discapacidades.

Fuente: Elaboración propia.

vo entre 0.2 y 0.4, valores sugeridos por Louviere, Hensher y Swait (2000) como representativos de buen ajuste. 
dad de participar en el mercado laboral depende en gran medida del género y de estar, o no, en situación de discapacidad, con efectos negativos para las mujeres y las personas en esta condición. Al controlar las diferentes variables (demográficas, de formación académica y geográficas, entre otras), los resultados indican que las mujeres tienen una probabilidad relativa de participar 18.8 veces inferior a la de los hombres y que las personas sin discapacidad cuadriplican su probabilidad de participar en el mercado de trabajo de las que padecen discapacidad. Ello, confirma los diferentes análisis realizados por la Organización Mundial de la Salud (2011; 2013), en los que se llama la atención respecto a la necesidad de planificar y ejecutar prontas acciones de política pública para eliminar estas desigualdades, que siguen profundizándose aún más en los países en vías de desarrollo (Organización Mundial de la Salud, 2011). En el cuadro 5, también destaca el esperado efecto positivo de la formación educativa, ya que, en la población total, entre mayor sea el nivel de estudios, mayor es la probabilidad de poder participar en el mercado laboral (respecto al grupo de referencia de los analfabetas), lo que es especialmente favorable para el rango de 25 a 44 años de edad (comparado con el grupo de referencia, de 12 a 24 años), mientras que la oportunidad relativa de participar decae perceptiblemente entre los individuos mayores de 59 años.

En términos de ingresos per cápita por hogar, todos los grupos tienen un efecto positivo, destacando la categoría entre COP 700 001-COP 1050 000, con la mayor probabilidad relativa de participar en el mercado laboral. Asimismo, aunque el nivel de estudios de los padres que más refuerza la probabilidad de participar es el superior, los coeficientes no resultan estadísticamente significativos para ningún nivel educativo de los padres. A su vez, estar casado implica una oportunidad relativa de participar 1.39 veces inferior a la de una persona de otro estado civil, efecto negativo que también se da, aunque en menor magnitud, si se es residente en una metrópoli como Bogotá, DC, Valle del Cauca o Antioquia. Sobre esto último, existe evidencia en la literatura internacional, la que reporta que vivir en ciudades no muy grandes está asociado con una mayor probabilidad de estar empleado (Malo, 2004).

Por otra parte, los resultados de la ecuación de participación laboral por género para personas sin discapacidad (cuadro 6) muestran que la oportunidad relativa de participar aumenta en mayor medida para las mujeres si se encuentran entre los 45 y los 59 años, mientras que los hombres tienen más posibilidades entre los 25 y los 44 años (en comparación con el grupo de referencia más joven). No obstante, para ambos sexos, tener 60 años o más incide negativamente 
Cuadro 6. Estimaciones de la probabilidad de participar en el mercado de trabajo

Modelo de regresión logística por género de personas sin discapacidad

\begin{tabular}{|c|c|c|c|c|c|c|}
\hline \multirow[t]{2}{*}{ Variables } & \multicolumn{3}{|c|}{ Mujeres } & \multicolumn{3}{|c|}{ Hombres } \\
\hline & Coeficiente & $O R^{*}$ & $1 / O R$ & Coeficiente & $O R^{*}$ & $1 / O R$ \\
\hline Constante & $-1.3723 * *$ & 0.2535 & 3.945 & $2.4152 * *$ & 11.1920 & \\
\hline Edad (25-44 años) & $0.9710 * *$ & 2.6407 & & $1.5652 * *$ & 4.7838 & \\
\hline Edad (45-59 años) & $1.1400 * *$ & 3.1269 & & $0.3959 * *$ & 1.4857 & \\
\hline Edad (más de 59 años) & -0.2466 & 0.7815 & 1.28 & $-1.8685^{* *}$ & 0.1544 & 6.479 \\
\hline Educación padres - primaria & 0.0783 & 1.0815 & & 0.0729 & 1.0757 & \\
\hline Educación padres - secundaria & 0.1173 & 1.1245 & & -0.1787 & 0.8363 & 1.196 \\
\hline Educación padres - superior & 0.0594 & 1.0612 & & -0.0188 & 0.9814 & 1.019 \\
\hline Casado & $-0.5502 * *$ & 0.5768 & 1.734 & -0.0480 & 0.9531 & 1.049 \\
\hline Metrópoli & 0.0168 & 1.0169 & & $-0.4126 * *$ & 0.6619 & 1.511 \\
\hline Educación propia - primaria & 0.0596 & 1.0614 & & $0.1616 * * * *$ & 1.1754 & \\
\hline Educación propia - secundaria & $0.3758 * * *$ & 1.4562 & & -0.1410 & 0.8685 & 1.151 \\
\hline Educación propia - superior & $1.2464 * *$ & 3.4777 & & 0.2074 & 1.2305 & \\
\hline $\begin{array}{l}\text { Ingreso per cápita } \\
\text { (COP } 350 \text { 001-COP } 700 \text { 000) }\end{array}$ & $0.8742 * *$ & 2.3969 & & $0.1313 * * * *$ & 1.1403 & \\
\hline $\begin{array}{l}\text { Ingreso per cápita } \\
\text { (COP } 700001 \text {-COP } 1050 \text { 000) }\end{array}$ & $1.3521 * *$ & 3.8657 & & -0.1292 & 0.8788 & 1.138 \\
\hline $\begin{array}{l}\text { Ingreso per cápita } \\
\text { (COP } 1050 \text { 001-COP } 1400000)\end{array}$ & $1.4018 * *$ & 4.0626 & & $-0.3983 * *$ & 0.6715 & 1.489 \\
\hline $\begin{array}{l}\text { Ingreso per cápita } \\
\text { (más de COP } 1400 \text { 001) }\end{array}$ & $1.6101 * *$ & 5.0033 & & $-0.2387 * * * *$ & 0.7877 & 1.27 \\
\hline Subsidio o pensión & $0.1539 * *$ & 1.1663 & & $0.2031 * * *$ & 1.2252 & \\
\hline Hijos o embarazada & $-0.1901 * * *$ & 0.8269 & 1.209 & & & \\
\hline$R^{2}$ de McFadden & 0.2035 & & & 0.2303 & & \\
\hline
\end{tabular}

* $O R=$ razones de probabilidad relativa.

** Parámetros estadísticamente significativos para $\alpha=1 \%$.

*** Parámetros estadísticamente significativos para $\alpha=5 \%$.

*** Parámetros estadísticamente significativos para $\alpha=10 \%$.

Nota: Porcentaje global de aciertos: mujeres, $65.37 \%$; hombres, $81.47 \%$.

Variables de referencia: edad (12-24 años), educación padres-analfabeta, otro estado civil, otras regiones, educación propia-analfabeta, ingreso per cápita (COP 0-COP 350 000), sin subsidio ni pensión, sin hijos (para el caso de las mujeres).

Fuente: Elaboración propia. 
en la probabilidad de estar empleado, lo que coincide con lo hallado en otros países (Lambrinos, 1981; Eide y Kamaleri, 2009). Asimismo, los estudios de nivel superior son los que más influyen en la oportunidad relativa de participar, con mayor impacto en el género femenino. ${ }^{20}$ De igual manera, hombres y mujeres sin discapacidad que se encuentran casados presentan una probabilidad relativa de participar 1.73 y 1.05 veces menor, respectivamente, que la de las personas en otro estado civil.

A partir del cuadro 6, se observa que los diferentes niveles educativos de los padres, sin ser significativos estadísticamente para ningún género, afectan positivamente la probabilidad relativa de participar en el mercado laboral en el caso de las mujeres, mientras que para los hombres, tener padres con estudios secundarios o superiores surte efectos adversos en la participación, en comparación con el grupo de referencia con padres analfabetas. A diferencia de los hombres, las mujeres sin discapacidad poseen siempre una mayor probabilidad relativa de participar, en las diferentes categorías de ingresos per cápita por hogar al compararse con la de referencia (COP 0 -COP 350000$).{ }^{21}$ En términos de subsidios o pensiones, existe un leve efecto positivo y significativo de estas transferencias, en ambos sexos, sobre la oportunidad de participar en el mercado laboral.

A su vez, el cuadro 7 muestra que para el género femenino en condición de discapacidad viene a ser determinante el grado de educación de los padres, ya

${ }^{20}$ El nivel de primaria es el único significativo estadísticamente para el género masculino, resultado evidentemente cierto si se observa desde una perspectiva más desagregada, a la luz de los estratos socioeconómicos, ya que en las clases populares y clases medias bajas la deserción escolar es sensiblemente menor entre las mujeres que entre los hombres, quienes, generalmente entre los 12 y los 15 años, entran a competir el mercado laboral (Maurizio, 2010; Villamizar, 2011). La importancia del nivel de estudios en el género femenino se sustenta en que a finales del siglo pasado, hubo un cambio de paradigma entre las mujeres de diferentes clases sociales (Organización Internacional del Trabajo, Comisión Económica para América Latina y el Caribe y Organización de las Naciones Unidas, 2013), quienes incluyeron a la educación y al empleo futuro como parte de sus proyectos de vida, en la búsqueda de una mayor independencia de las labores domésticas y dada la menor importancia que tiene actualmente la maternidad en todos los sectores sociales (especialmente entre las mujeres de clases medias y altas) (Villamizar, 2011; Organización Internacional del Trabajo, Comisión Económica para América Latina y el Caribe y Organización de las Naciones Unidas, 2013).

${ }^{21} \mathrm{Al}$ considerar los ingresos del hogar como indicador indirecto de la clase social y de acuerdo con Dávila (2006), las familias generalmente adoptan estrategias que tienen por finalidad la inserción laboral de sus miembros (mediante relaciones de poder, redes profesionales, etcétera). Esto sería congruente con el hecho de tener mayores razones de probabilidad relativa entre más alto sea el nivel de ingresos familiares, premisa que solo se cumple en el presente estudio por parte de la población femenina sin discapacidad. 
Cuadro 7. Estimaciones de la probabilidad de participar en el mercado de trabajo Modelo de regresión logística por género para personas con discapacidad

\begin{tabular}{|c|c|c|c|c|c|c|}
\hline \multirow[t]{2}{*}{ Variables } & \multicolumn{3}{|c|}{ Mujeres } & \multicolumn{3}{|c|}{ Hombres } \\
\hline & Coeficiente & $O R^{*}$ & $1 / O R$ & Coeficiente & $O R^{*}$ & $1 / O R$ \\
\hline Constante & -0.4346 & 0.6476 & 1.5443 & $1.9656 * *$ & 7.1389 & \\
\hline Edad (25-44 años) & $1.1983 * * *$ & 3.3143 & & 0.1377 & 1.1476 & \\
\hline Edad (45-59 años) & 0.8141 & 2.2571 & & -0.6436 & 0.5254 & 1.9033 \\
\hline Edad (más de 59 años) & 0.3532 & 1.4236 & & $-2.2288 * *$ & 0.1077 & 9.2886 \\
\hline Educación padres - primaria & -0.5984 & 0.5497 & 1.8192 & $0.2722 * * * *$ & 1.3129 & \\
\hline Educación padres - secundaria & $-1.2738 * * * *$ & 0.2798 & 3.5746 & $-0.2430 * * * *$ & 0.7843 & 1.2750 \\
\hline Educación padres - superior & $-2.8524 * * * *$ & 0.0577 & 17.3297 & $-0.3260 * * * *$ & 0.7218 & 1.3854 \\
\hline Casado & -0.1663 & 0.8468 & 1.1810 & $0.1644 * * * *$ & 1.1787 & \\
\hline Metrópoli & $0.9441 * * *$ & 2.5705 & & $-0.2350 * * * *$ & 0.7905 & 1.2650 \\
\hline Educación propia - primaria & -0.2099 & 0.8106 & 1.2336 & 0.1430 & 1.1538 & \\
\hline Educación propia - secundaria & 0.5488 & 1.7312 & & 0.2683 & 1.3077 & \\
\hline Educación propia - superior & $1.7051 * * * *$ & 5.5021 & & $0.6296 * * * *$ & 1.8768 & \\
\hline $\begin{array}{l}\text { Ingreso per cápita } \\
\text { (COP } 350001-C O P 700000)\end{array}$ & $0.9050 * * * *$ & 2.4718 & & $0.3011 * * * *$ & 1.3513 & \\
\hline $\begin{array}{l}\text { Ingreso per cápita } \\
\text { (COP } 700001 \text {-COP } 1050 \text { 000) }\end{array}$ & $1.6693 * * *$ & 5.3082 & & -0.4388 & 0.6448 & 1.5508 \\
\hline $\begin{array}{l}\text { Ingreso per cápita } \\
\text { (COP 1050001-COP } 1400 \text { 000) }\end{array}$ & -0.3111 & 0.7326 & 1.365 & -0.1311 & 0.8771 & 1.1401 \\
\hline $\begin{array}{l}\text { Ingreso per cápita } \\
\text { (más de COP } 1400 \text { 001) }\end{array}$ & $1.5515 * * * *$ & 4.7186 & & $-0.2289 * * * *$ & 0.7954 & 1.2572 \\
\hline Subsidio o pensión & -0.0775 & 0.9255 & 1.0805 & -0.2391 & 0.7873 & 1.2701 \\
\hline Hijos o embarazada & 0.2285 & 1.2567 & & & & \\
\hline \multicolumn{7}{|l|}{ Tipo de discapacidad } \\
\hline Moverse o caminar & $-1.3243 * * *$ & 0.2660 & 3.7596 & $-1.0647 * *$ & 0.3448 & 2.8999 \\
\hline En brazos o manos & -0.6180 & 0.5390 & 1.8552 & $-0.7032 * * *$ & 0.4950 & 2.0203 \\
\hline En visión & $-1.0400 * * *$ & 0.3535 & 2.8291 & -0.2535 & 0.7761 & 1.2886 \\
\hline En escucha & -0.4455 & 0.6405 & 1.5612 & -0.3278 & 0.7205 & 1.3880 \\
\hline En habla & $-2.1068 * *$ & 0.1216 & 8.2222 & -0.4736 & 0.6228 & 1.6057 \\
\hline $\begin{array}{l}\text { En entendimiento o } \\
\text { aprendizaje }\end{array}$ & 0.7930 & 2.2100 & & $-1.4062 * *$ & 0.2451 & 4.0805 \\
\hline $\begin{array}{l}\text { Dificultad de relacionarse } \\
\text { con los demás por problemas } \\
\text { mentales o emocionales }\end{array}$ & $-1.7800 * * *$ & 0.1690 & 5.9310 & $-1.9808 * *$ & 0.1380 & 7.2483 \\
\hline $\begin{array}{l}\text { Para bañarse, vestirse, } \\
\text { alimentarse por sí mismo }\end{array}$ & $580 * * *$ & 0.1540 & 6.4750 & $-1.5135 * *$ & 0.2201 & 4.5426 \\
\hline Otra limitación permanente & $-0.9130 * * * *$ & 0.4010 & 2.4920 & $-1.5556 * *$ & 0.2111 & 4.7379 \\
\hline$R^{2}$ de McFadden & 0.2125 & & & 0.2427 & & \\
\hline
\end{tabular}

* $O R=$ razones de probabilidad relativa. ** Parámetros estadísticamente significativos para $\alpha=1 \%$. *** Parámetros estadísticamente significativos para $\alpha=5 \%$. ** Parámetros estadísticamente significativos para $\alpha=10 \%$.

Nota: Porcentaje global de aciertos: mujeres: $71.93 \%$, hombres: $74.04 \%$. Variables de referencia: edad (12-24 años), educación padres-analfabeta, otro estado civil, otras regiones, educación propia-analfabeta, ingreso per cápita (COP 0-COP 350 000), sin subsidio ni pensión, sin hijos (para el caso de las mujeres).

Fuente: Elaboración propia. 
que si el nivel de estudios de éstos es de educación superior, su probabilidad de participar es 17.32 veces inferior que la de una mujer en condición de discapacidad con padres analfabetas. Este comportamiento tiene similar dirección, aunque no la misma magnitud, en el caso de los hombres en condición de discapacidad con padres que poseen estudios secundarios y universitarios.

De acuerdo con este mismo cuadro, un mayor nivel educativo, específicamente estudios secundarios y superiores, facilita la actividad laboral para ambos sexos, ya que incrementa la probabilidad de participar en comparación con los analfabetos, resultados afines a los de Kidd, Ferko y Sloane (2000), García-Serrano y Malo (2002), Malo (2004) y Dávila (2006). Para el género masculino en condición de discapacidad, ingresos per cápita por hogar mayores a COP 700000 (siendo significativos sólo los superiores a COP 1400 000), generan un impacto negativo sobre la probabilidad relativa de inserción al mercado de trabajo, lo que estaría sustentado en la satisfacción por el solo hecho de tener lo necesario para subsistir, lo que optimiza su tasa de ocio/trabajo.

El habitar en una metrópoli juega a favor de las mujeres en condición de discapacidad, cosa que, por el contrario, no ocurre con los hombres. ${ }^{22} \mathrm{~A}$ su vez, el matrimonio tiene un efecto positivo sobre los varones con discapacidad, dado que la probabilidad relativa de participar en el mercado laboral es 1.18 veces superior a la de quienes están en otro estado civil. A su vez, el efecto es negativo, aunque no significativo, para las mujeres en condición de discapacidad, con una oportunidad 1.18 veces inferior respecto a quienes no están casadas.

Uno de los puntos más importantes de esta investigación son las implicaciones de los diferentes tipos de discapacidad. Al respecto, puede observarse que para el género femenino las limitaciones permanentes en el habla y para bañarse, vestirse, alimentarse por sí mismas, son las que menos probabilidades ofrecen al hecho de estar activas laboralmente. Todas las demás discapacidades también tienen impactos negativos, excepto en el caso de las mujeres con problemas de entendimiento o aprendizaje, aunque su efecto no resulta significativo estadísticamente.

${ }^{22}$ Esto es similar en el caso de las personas sin discapacidad. Podría deberse a que en la metrópolis (asociadas a centros políticos, económicos, industriales, etcétera) existe un mayor acatamiento de las leyes formales e informales sobre equidad de género, lo que implica, por sí mismo, una relación positiva respecta a la actividad laboral femenina. Sería el caso contrario el de las áreas rurales y las ciudades pequeñas, donde el patriarcado todavía se halla arraigado y el varón aún es el trabajador del hogar, dejando a la pareja el cuidado del hogar y/o de los hijos (Becerra et al., 2011; Turbay, 2005). 
En lo referente al género masculino, todas las discapacidades tienen los efectos negativos esperados, pero la mayor disminución de la probabilidad relativa de participar se asocia a la dificultad de relacionarse con los demás por problemas mentales o emocionales, ${ }^{23} \mathrm{o}$ a otra limitación permanente. Asimismo, se halló que el efecto acumulado de los diferentes tipos de discapacidad es mayor para las mujeres, aunque no mucho, que para los hombres, lo que contrasta con los resultados de Dávila (2006) y Wilkins (2003), quienes encuentran un efecto negativo superior para el género masculino en diferentes partes del mundo.

Por otro lado, al comparar las estimaciones por género entre individuos con discapacidad y sin ella, se encontró que las mujeres tienen una mayor probabilidad relativa de participar en el mercado de trabajo si son más jóvenes, caso similar al de los hombres en condición de discapacidad, quienes empiezan a sufrir efectos negativos si son mayores de 44 años. De igual forma, la probabilidad de participar se incrementa para el género femenino con discapacidad cuando se tienen hijos o se encuentra en estado de embarazo.

Las principales diferencias entre mujeres con y sin discapacidad radican en los efectos negativos del nivel educativo de los padres para las primeras y el efecto positivo del subsidio o pensión para las segundas. A su vez, las mayores divergencias entre hombres con y sin discapacidad se encuentran en el impacto negativo de tener entre 25 y 49 años de edad, para unos, y los efectos negativos de estar casado para los otros. Finalmente, en materia de subsidios y pensiones, tema en el que la mayor parte de la literatura internacional aún no tiene consenso (Parsons, 1980; Bound, 1989), los efectos sobre la participación en el mercado laboral de la población sin discapacidad son positivos (cuadro 6), mientras que resultan negativos para las personas con discapacidad -aunque de pequeña magnitud y no significativos estadísticamente (cuadro 7)-, reflejando una leve falta de incentivo por parte de quienes padecen limitaciones permanentes para encontrarse activos laboralmente.

\section{CONCLUSiones}

Aunque en Colombia se ha legitimado y consolidado un marco legal para la inclusión integral de personas en condición de discapacidad, de manera análoga a otras partes del mundo, la desigualdad sigue siendo una problemática continua y

${ }^{23}$ En concordancia con O’Donnell (1998), quien establece que las enfermedades mentales disminuyen en gran medida la probabilidad relativa de estar laboralmente activo. 
creciente, dada la vulnerabilidad que sufren en diferentes escenarios de la sociedad. Los resultados del presente estudio ponen de manifiesto las pocas oportunidades que siguen existiendo para quienes viven en situación de discapacidad en términos laborales - algo vital tanto para la integración social del individuo como para el desarrollo de su personalidad-, ya sea por razones de limitación física o mental, de discriminación en el mercado de trabajo y/o del poco impacto de las leyes que los cobijan.

Es importante retomar la preocupación expuesta por Lugo y Seijas (2012) respecto a la actualidad de las personas en condición de discapacidad en Colombia, ya que a pesar de contar con una abundante legislación en la materia, diversas circunstancias (económicas, educativas, laborales, entre otras) les siguen siendo menos favorables que a la población en general, como fue posible observar en el análisis descriptivo, que muestra la existencia de una mayor proporción de personas en condición de discapacidad analfabetas en comparación con el segmento sin discapacidad.

Con base en las estimaciones econométricas efectuadas, destaca dentro de los resultados esperados que el nivel de estudios de las personas en condición de discapacidad de ambos géneros impacta positivamente sobre la probabilidad relativa de participar en el mercado laboral (con un efecto mayor en las mujeres). Por el contrario, la influencia que tiene el grado de estudios de los padres es negativa, pues mientras más alto nivel educativo posean, más disminuyen las probabilidades de que sus hijos en condición de discapacidad incursionen en el mercado de trabajo. ${ }^{24}$

Respecto a las variables de salud, en la población masculina, aunque inciden negativamente en las probabilidades de emplearse, las limitaciones sensoriales son las que menos peso tienen dentro del conjunto de discapacidades (con relación al sexo femenino), mientras que los problemas mentales y de entendimiento o aprendizaje tienen mayor influencia. Es el caso contrario de las mujeres, quienes enfrentan mayores dificultades para su inserción laboral por

\footnotetext{
${ }^{24}$ Este resultado sería indicativo de que los padres con altos niveles educativos, estrechamente asociados con buenos ingresos económicos, prefieren que sus hijos en condición de discapacidad no laboren, dado que ellos podrían asumir la responsabilidad de mantenerlos, brindándoles una apropiada calidad de vida. En este escenario, será necesario que el gobierno fomente cambios de mentalidad a través de programas de seguimiento psicológico para este tipo de núcleos familiares, con los que se oriente y se inculque la visión integral que deben tener los padres frente al trabajo por parte de un hijo en situación de discapacidad, mostrando el empleo como un bien, beneficioso para el estado mental y físico en la medida en que se adapte funcionalmente a un trabajo en el cual se sienta útil dentro de su entorno social.
} 
discapacidades relacionadas con la movilidad, la resistencia y la fuerza (en comparación con el sexo masculino), como las limitaciones para moverse o caminar y para bañarse, vestirse, alimentarse por sí mismas.

Es así, como las inferencias del presente análisis tienen implicaciones de suma importancia para el diseño de la política de empleo para este segmento de la población. Los datos aportados muestran necesidades de cambio social que están pendientes en el país, como es lidiar contra la negativa percepción generalizada, en términos laborales, de las personas con limitaciones físicas y/o mentales permanentes, a pesar de que en la mayoría de los casos pueden contribuir productivamente a una empresa.

En relación a los grupos más vulnerables, es necesario poner un mayor énfasis en programas de apoyo para mujeres en condición de discapacidad con hijos o en estado de embarazo, mediante el diseño de óptimas estrategias de capacitación y acompañamiento en el proceso de inserción laboral (la Ley 1618 (2013) podría verse como un primer acercamiento desde el ámbito legal). Es, asimismo, importante impulsar la creación de programas gubernamentales que proporcionen un apoyo contundente a la población con problemas de movilidad extrema (principalmente del género femenino), así como una mayor colaboración y seguimiento para integrar al mundo laboral a quienes sufran más de una discapacidad (sensorial, mental, de movilidad y/o de aprendizaje).

La presente investigación se puede considerar un primer acercamiento riguroso al tema, pero es necesario realizar estudios más detallados sobre el entorno laboral de las personas en condición de discapacidad, con el fin de abordar otros detalles fundamentales, como la incidencia del ámbito regional-municipal, la clase de puestos que ocupan y los salarios que perciben. Ahondar en esta línea, contribuirá a que se tome conciencia de la importancia de un pronto actuar por parte de los empresarios, las instituciones y los gobernantes, ya que es claro que todavía faltará mucho por indagar y aprender sobre esta importante temática en Colombia.

\section{REFERENCIAS BIBLIOGRÁFICAS}

Atijosan, Oluwarantimi; Foster, Allen; Jofret-Bonet, Mireia; Kuper, Hannah; Lavy, Christopher; Rischewski, Dorothea, y Simms, Victoria (2008), "Poverty and Musculoskeletal Impairment in Rwanda", Transactions of the Royal Society of Tropical Medicine and Hygiene, 102 (6), pp. 608-617.

Baldwin, Marjorie, y Johnson, William (1994), "Labor Market Discrimination against Men with Disabilities", The Journal of Human Resources, 29 (1), pp. 1-19. 
(1995), "Labor Market Discrimination against Women with Disabilities", Industrial Relations, 34 (4), pp. 555-577.

Bartel, Ann, y Taubman, Paul (1979), "Health and Labor Market Success: The Role of Various Diseases", Review of Economics and Statistics, 61 (1), pp. 1-8.

Becerra, Laura; Celiberti, Lilian; Erotegui, Susana; Mejía, Claudia; Ospina, Rosa; Samqui, Eva, y Zeballos, Molvina (2011), Consulta regional sobre la equidad de género. Bogotá, DC, Asociación Latinoamericana de Organizaciones de Promoción al Desarrollo, DC.

Becker, Gary (1971), The Economics of Discrimination, Chicago, University of Chicago Press.

Bound, John (1989), "The Health and Earnings of Rejected Disability Insurance Applicants", The American Economic Review, 79 (3), pp. 482-503.

Brazenor, Richard (2002), "Disabilities and Labour Market Earnings in Australia", Australian Journal of Labour Economics, 5 (3), pp. 319-334.

Cazes-Chaigne, Sandrine (2007), Discriminación por razones de discapacidad, Ginebra, Organización Internacional del Trabajo.

Constitución Política de Colombia (1991), Bogotá, DC, Panamericana.

Cortés, Juan (2015), "Servicios sociales: presente y futuro de la seguridad social", Revista Más Vida, 0 (24), pp. 44-47.

Council of Australian Governments (2011), National Disability Strategy 2010-2020, Canberra, Council of Australian Governments.

Cramer, Jan (2011), Logit Models from Economics and Other Fields, Cambridge, Cambridge University Press.

Dávila, Delia (2006), "Discapacidad y género. Un estudio de participación en el mercado de trabajo español", Moneda y Crédito, 0 (223), pp. 127-158.

Departamento Administrativo Nacional de Estadística (2013a), Base de Microdatos “Encuesta Nacional de Calidad de Vida 2013”, Bogotá, DC, DANE.

(2013b), Metodología Encuesta Nacional de Calidad de Vida, Bogotá, DC, DANE.

Decreto 2358 (1981), Bogotá, DC, Ministerio de Salud .

Departamento Nacional de Planeación (2004), Documento Conpes Social 80. Política pública nacional de discapacidad, Bogotá, DC, DNP.

(2013), Documento Conpes Social 166. Política pública nacional de discapacidad e inclusión social, Bogotá, DC, DNP.

Econometría Consultores (2012), Evaluación institucional y de resultados cualitativos a la política nacional de discapacidad. Informe final, Bogotá, DC, Departamento Nacional de Planeación. 
Eide, Arne; Loeb, Mitch, y Van Rooy, Gert (2003), Living Conditions among People with Activity Limitations in Namibia. A Representative National Survey, Oslo, SINTEF.

Eide, Arne, y Kamaleri, Yusman (2009), Living Conditions among People with Disabilities in Mozambique. A National Representative Study, Oslo, sINTEF. (2011), Living Conditions among People with Disabilities in Lesotho. A National Representative Study, Oslo, SINTEF.

Frieden, Lex (2003), "El Consejo Nacional sobre Discapacidad de Estados Unidos recomienda una política exterior inclusiva", Disability World, 0 (20), pp. 209-219.

Garavito, Diana (2014), "La inclusión de las personas con discapacidad en el mercado laboral colombiano, una acción conjunta”, tesis de Maestría, Universidad Nacional de Colombia.

García-Serrano, Carlos, y Malo, Miguel (2002), "Discapacidad y mercado de trabajo en la Unión Europea", Cuadernos Aragoneses de Economía, 12 (2), pp. 237-255.

Grossman, Michael, y Benham, Lee (1974), "Health, Hours and Wages", en M. Perlman (ed.), The Economics of Health and Medical Care, New York, John Wiley \& Sons, pp. 206-233.

Hernández-Licona, Gonzalo (2001), "Disability and the Labor Market in Latin America", Disability World, 0 (9). [en línea] Consultado el 20 de julio de 2014 en: http://www.disabilityworld.org/07-08_01/employment/labor1.shtml.

Kidd, Michael; Ferko, Ivan, y Sloane, Peter (2000), "Disability and the Labour Market: An Analysis of British Males", Journal of Health Economics, 19 (6), pp. 961-981.

Lambrinos, James (1981), "Health: A Source of Bias in Labor Supply Models", The Review of Economics and Statistics, 63 (2), pp. 206-212.

Ley 361 (1997), Bogotá, DC, Congreso de Colombia.

Ley 762 (2002), Bogotá, DC, Congreso de Colombia.

Ley 1306 (2009), Bogotá, DC, Congreso de Colombia.

Ley 1346 (2009), Bogotá, DC, Congreso de Colombia.

Ley 1429 (2010), Bogotá, DC, Congreso de Colombia.

Ley 1618 (2013), Bogotá, DC, Congreso de Colombia.

Loprest, Pamela; Rupp, Kalman, y Sandell, Steven (1995), "Gender, Disabilities, and Employment in the Health and Retirement Study", Journal of Human Resources, 30 (4), supplement, pp. s293-s318.

Louviere, Jordan; Hensher, David, y Swait, Joffre (2000), Stated Choice Methods, New York, Cambridge University Press.

Lugo, Luz, y Seijas, Vanessa (2012), "La discapacidad en Colombia: Una mirada 
global”, Revista Colombiana de Medicina Física y Rehabilitación, 22 (2), pp. 164-179.

Malo, Miguel (2004), “Cómo afectan las discapacidades a la probabilidad de ser activo en España? Un análisis empírico con datos de la Encuesta sobre Discapacidades, Deficiencias y Estado de Salud de 1999”, Cuadernos de Economía, 27, pp. 75-108.

Malo, Miguel, y Pagán, Ricardo (2012), “Wage Differentials and Disability across Europe: Discrimination and/or Lower Productivity?”, International Labour Review, 151 (1-2), pp. 43-60.

Maurizio, Roxana (2010), Enfoque de género en las instituciones laborales y las políticas del mercado de trabajo en América Latina, Macroeconomía del Desarrollo 104, Santiago de Chile, CEPAL.

McFadden, Daniel (1974), "Conditional Logit Analysis of Qualitative Choice Behavior", en P. Zarembka (ed.), Frontiers in Econometrics, New York, Academic Press, pp. 105-142.

Meseguer-Santamaría, María; Mondéjar-Jiménez, José; Mondéjar-Jiménez, Juan, y Vargas-Vargas, Manuel (2009), "Impact of Social Factors on Labour Discrimination of Disabled Women”, Research in Developmental Disabilities, 30 (6), pp. 1115-1123.

Ministerio de la Protección Social (2008), Procesos de inclusión laboral en la política pública de discapacidad en Colombia, Bogotá, DC, Dirección de Promoción del Trabajo.

- (2010), Normas integrales de protección a la discapacidad en Colombia, Bogotá, DC, Viceministerio de Relaciones Laborales.

Mitra, Sophie, y Mizunoya, Suguru (2013), "Is There a Disability Gap in Employment Rates in Developing Countries?”, World Development, 42, pp. 28-43.

Mitra, Sophie, y Sambamoorthi, Usha (2008), "Disability and the Rural Labor Market in India: Evidence for Males in Tamil Nadu", World Development, 36 (5), pp. 934-952.

Mortensen, Dale (1986), "Job Search and Labor Market Analysis”, en O. Ashenfelter y R. Layard (eds.), Handbook of Labour Economics, vol. 2, Amsterdam, NorthHolland, pp. 849-919.

O’Donnell, Owen (1998), “The Effect of Disability on Employment Allowing for Work Incapacity", documento de discusión, Studies in Economics 9813, School of Economics, University of Kent.

Organización Iberoamericana de Seguridad Social (2014), Medidas para la promoción del empleo de personas con discapacidad en Iberoamérica, Madrid, oIss. 
Organización Internacional del Trabajo, Comisión Económica para América Latina y el Caribe y Organización de las Naciones Unidas (2013), Informe regional. Trabajo decente e igualdad de género, Santiago de Chile, CEPAL/FAO/ONU Mujeres/ PNUD/OIT.

Organización Mundial de la Salud (2011), Informe mundial sobre la discapacidad, La Valeta, oms.

- (2013), "Discapacidad y salud: Nota descriptiva 352", en Centro de prensa. Consultado el 21 de octubre de 2014, en: http://www.who.int/mediacentre/ factsheets/fs352/es/.

Parsons, Donald (1980), "The Decline in Male Labor Force Participation", Journal of Political Economy, 88(1), pp. 117-134.

(1984), "Disability Insurance and Male Labor Force Participation: A Response", Journal of Political Economy, 92 (3), pp. 542-549.

Rogerson, Richard; Shimer, Robert, y Wright, Randall (2005), "Search-theoretic Models of the Labor Market: A Survey", Journal of Economic Literature, 43 (4), pp. 959-988.

Samboni, Milvia, y Torres, María (2015), "La inclusión laboral fortalece la responsabilidad social empresarial", en Universidad Nacional de Colombia, Memorias del Encuentro Nacional de Investigación y Desarrollo 2015, Manizales, Universidad Nacional de Colombia, s.p.

Stang, María (2011), Las personas con discapacidad en América Latina: del reconocimiento jurídico a la desigualdad real, Población y Desarrollo 103, Santiago de Chile, CEPAL.

Turbay, María (2005), "Una mirada de género a la Encuesta de Calidad de Vida 2003: Jefatura de hogar y seguridad social en Colombia", en Programa de las Naciones Unidas para el Desarrollo y Consejería Presidencial para la Equidad de la Mujer (eds.) Investigaciones sobre género y desarrollo en Colombia, Bogotá, DC, Panamericana Formas e Impresos, pp. 13-64.

Villamizar, Eugenia (2011), Uso del tiempo de mujeres y hombres en Colombia. Midiendo la inequidad, Asuntos de Género 107, Santiago de Chile, CEPAL.

Wilkins, Roger (2003), "Labor Markets Outcomes and Welfare Dependence of Persons with Disabilities in Australia", Melbourne Institute Working Paper 2/03. 